\title{
Vidalı Meyve Sıkma Presi Tasarımı, Yapısal Analizi, İmalatı ve Veriminin Araştırılması
}

\author{
*1Harun Koçak \\ *1TUSAŞ Kazan MYO, Mot. Arç. ve Ulş. Tek. Bölümü, Gazi Üniversitesi, Turkey
}

\begin{abstract}
Özet
Ülkemizde bir çok meyve çeşidi yetiştirilmekte ve bunların bir kısmından pekmez yapılmaktadır. Pekmez, fabrikalarda modern yöntemlerle üretilirken kırsal bölgelerde genellikle eski yöntemlerle üretilmektedir. Bu çalışmada, pekmez üretimi yapılırken meyvelerin sıkılarak suyunun elde edilmesi için meyve sıkma presi tasarlanmış ve imal edilmiş̧ir. CAD programında meyve sıkma presinin 3B modeli oluşturulmuş, gerekli hesaplamaları yapılmış ve iskelet kısmı yapısal olarak analiz edilmiştir. Yapılan hesaplamalara göre tasarlanan meyve sıkma presi için uygun elektrik motoru ve kayış seçimi yapılmıştır. Kayış-kasnak ve vida mekanizması sayesinde kırsal bölgelerde kolayca kullanılabilecek bir tasarım ortaya çıkmıştır. İmal edildikten sonra presle elma püresi sıkılarak verimliliği incelenmiştir. Yapılan hesaplamalarda, meyve sıkma presinin $10000 \mathrm{~N}$ sıkma kuvveti uygulayabilmesi için 1,5 kW gücünde ve $1410 \mathrm{dev} / \mathrm{dak}$ elektrik motoru seçilmesi gerektiği bulunmuştur. Yapılan analizde iskelet yapının maksimum gerilmesi 215,33 MPa ve yer değiştirme miktarı 1,69 mm olduğu görülmüştür. İmal edildikten sonra meyve sıkma presiyle püre haline getirilmiş elma sıkılmıştır. Elma püresinin \% 71 oranında sıkılarak suyunun çıkartılabildiği tespit edilmiştir.
\end{abstract}

Anahtar kelimeler: Meyve Sikma Presi, Tasarım, Yapısal Analiz, Sikma Verimi.

\begin{abstract}
Many fruit varieties are grown in our country and molasses is made from some of them. The molasses is produced in the factories by modern methods. However, it still continues with conventional methods in rural areas. In this study, the fruit juicing press was designed and manufactured to obtain the juicing of the fruits in producing molasses. In the CAD program, a 3D model of the juicing press was created, necessary calculations were made and the skeleton structure was analyzed. Appropriate electric motor and belt selection were made for the juicing press designed according to the calculations. Thanks to the belt-pulley and screw mechanism, a design that can be used easily in rural areas has emerged. After being manufactured, the apple puree was pressed with press and its efficiency was examined. In the calculations, it has been found that the juicing press must have a power of $1,5 \mathrm{~kW}$ and a $1410 \mathrm{rpm}$ electric motor for a clamping force of $10000 \mathrm{~N}$. In the analysis, it was observed that the maximum stress of the skeletal structure was $215.33 \mathrm{MPa}$ and the displacement amount was $1.69 \mathrm{~mm}$. Water in apple puree was extracted by $71 \%$ with the fruit juicing press.
\end{abstract}

Key words: Juicing Press, Design, Structural Analysis, Crimping Efficiency

\section{Giriş}

Ülkemize özgü bir gida maddesi olan pekmez fabrikalarda ve kırsal bölgelerde üretilmektedir. Pekmez üretimi için ilk önce meyvelerin sıkılarak suyunun çıkarılması gerekmektedir. Bu işlem

*Corresponding author: Address: TUSAŞ Kazan MYO, Mot. Arç. ve Ulş. Tek. Bölümü, Gazi

Üniversitesi, Ankara, Türkiye. E-mail address: : harunkocak@gazi.edu.tr, Phone: +90-312-800-1608 
fabrikalarda modern yöntemlerle yapılmasına rağmen kırsal bölgelerde genellikle eski yöntemlerle devam etmektedir [1]. Yaygın olarak üzümden üretilmesinin yanı sıra elma, dut, kayıs1, erik ve incir gibi meyvelerden de üretilmektedir [2]. Elma dünyada toplam meyve üretiminin yaklaşık \%12'sini oluşturmakta ve muzdan sonra ikinci sırada yer almaktadır [3]. Bu yüzden çok yetiştirilen bir meyve olması nedeniyle israf olmaması için farklı değerlendirme yöntemlerinin geliştirilmesi gerekmektedir. Pekmezi yapılan diğer meyvelere göre daha sert oldukları için de suyunun çıkartılması diğer meyvelerden daha zordur. Bu tür meyveler önce püre makinesinden geçirilmekte ve saha sonra presle sıkılarak suyu çıkartılmaktadır [4]. Özellikle kırsal bölgelerde bu tür işlemler için hem basit hem de kullanışlı makinelere ihtiyaç duyulmaktadır.

Bir makinenin tasarımı ve imalatı yapılırken kullanım alanına uygunluk, ekonomiklik ve basitlik gibi kriterler göz önünde bulundurulmalıdır [5]. Aynı zamanda yapılan tasarım, gereksinimlere yanıt verebilmeli ve günlük hayattaki problemlerin çözümünde fayda sağlamalıdır [6]. Kırsal bölgede, makineleri etkileyen şartların durumu ve kullanılabilecek enerji olanaklarının kısıtlı olması bakımından genellikle basit, ekonomik ve kullanışlı makineler tercih edilmektedir.

$\mathrm{Bu}$ çalışmada, pekmez üretimi yapılırken kırsal bölgelerde meyvelerin sıkılarak suyunun çıkarılması için vidalı meyve sıkma presi tasarlanmış ve imal edilmiştir. CAD programında meyve sıkma presinin 3B modeli oluşturulmuş, gerekli hesaplamaları yapılmış ve iskelet kısmı yapısal olarak analiz edilmiştir. İmal edildikten sonra presle elma püresi sıkılarak verimliliği incelenmiştir.

\section{Malzeme ve metot}

Meyve sıkma presinin her bir parçası Solidworks programında tasarlanmış ve ardından tasarım montajı oluşturulmuştur (Tablo 2). Tasarımın tahrik sisteminde, elektrik motorundan alınan dairesel hareket kayış kasnak sitemiyle vida mekanizmasına aktarılmış ve sıkma işlemi için itme hareketine dönüştürülmüştür. Yaklaşık olarak 1 ton itme kuvveti sağlayabilmesi için hesaplamalar yapılmış ve gerekli elektrik motoru gücü bulunarak motor seçimi yapılmıştır. Hesaplamalara göre seçilen elektrik motoru 1,5 kW'dır. Sonrasında seçilen elektrik motorundan iletilecek güce göre kayış hesaplamaları ve seçimi yapılmıştır. Presin yapısal iskelet kısmı, çap1 21,3 mm olan St 37-3 çelik borulardan kaynaklanarak oluşturulmuştur. Yapısal iskeletin CAD modeli parasolid.x_t formatında kaydedilmiş ve 1 tonluk itme kuvvetine göre ANSYS programında yapısal analiz yapılmıştır. Gerekli hesaplamalar ve analizlerin ardından presin üretimi yapılmıştır. Son olarak presle elma püresi sıkılarak verimliliği incelenmiştir. Meyve sıkma presinin yapımında kullanılan malzemelerin mekanik özellikleri Tablo 1'de verilmiştir.

Tablo 1. Kullanılan malzemelerin kimyasal ve mekanik özellikleri

\begin{tabular}{ccccccccc}
\hline Malzeme & \multicolumn{4}{c}{ Kimyasal bileşim (ă̆ırlıça \%) } & \multicolumn{3}{c}{ Mekanik özellikler } \\
\hline 1.0116 & $\mathrm{C}$ & $\mathrm{Mn}$ & $\mathrm{P}$ & $\mathrm{S}$ & $\mathrm{Si}$ & Akma D. (MPa) & Çekme D. (MPa) & Uzama \% \\
\cline { 2 - 9 } St 37-3 & 0,17 & 1,4 & 0,035 & 0,035 & & 235 & $360-510$ & 24 \\
\hline Ck 45 & 0,5 & 0,8 & 0,045 & 0,045 & 0,4 & 430 & $650-800$ & 16 \\
\hline
\end{tabular}


Tablo 2. Montaj listesi ve resmi

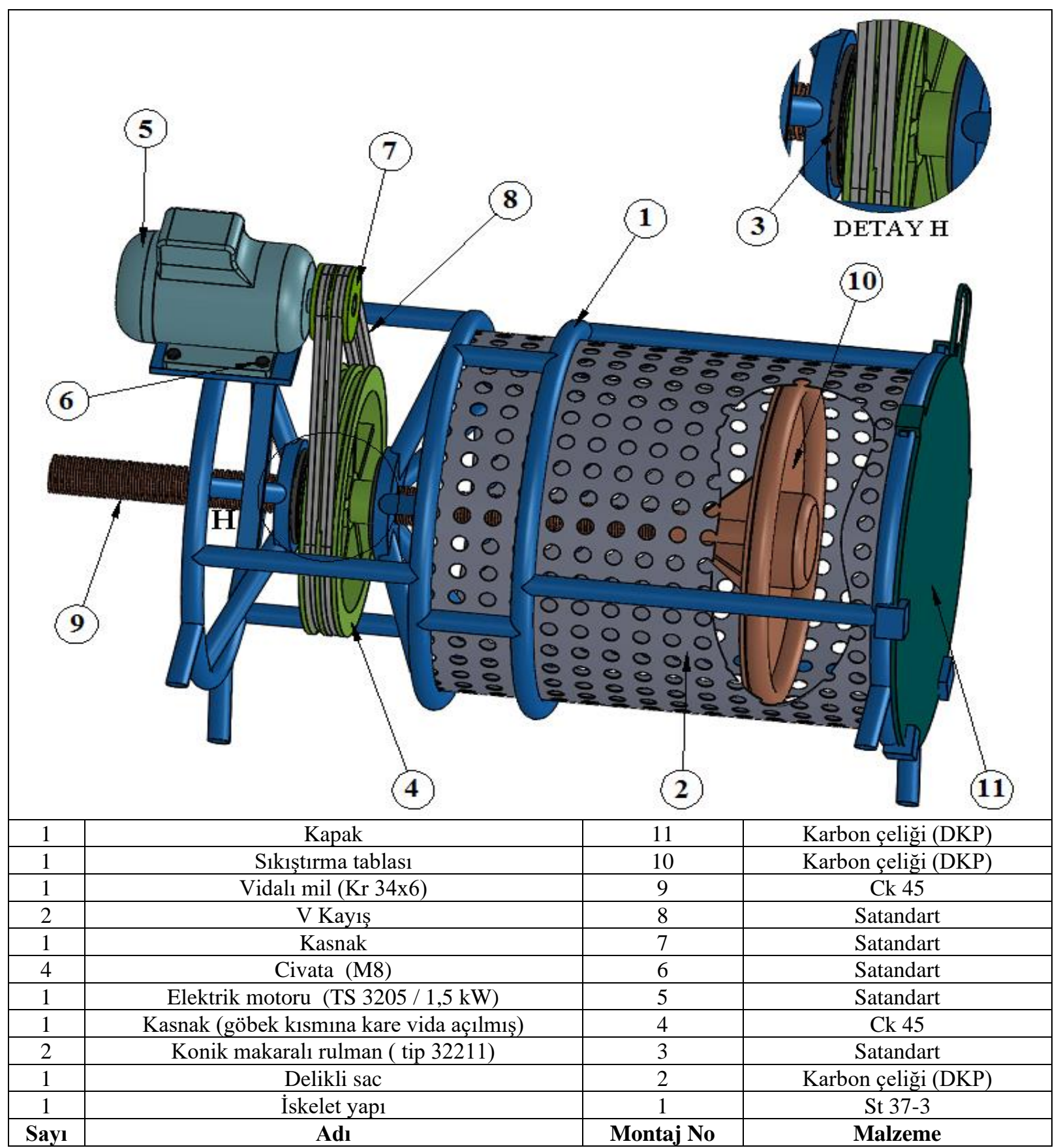




\section{Tasarım}

\subsection{Tahrik sistemi ve motor seçimi}

Şekil 1'de sistemin tahrik mekanizması verilmiştir. Görüldüğü gibi elektrik motorundan alınan dairesel hareket kayış kasnak sitemiyle vida mekanizmasına (Şekil 2) aktarılmış ve doğrusal itme hareketine dönüştürülmüştür. Meyve sıkma presinin yaklaşık olarak sıkma kuvvetinin 1 ton olması istenmektedir.

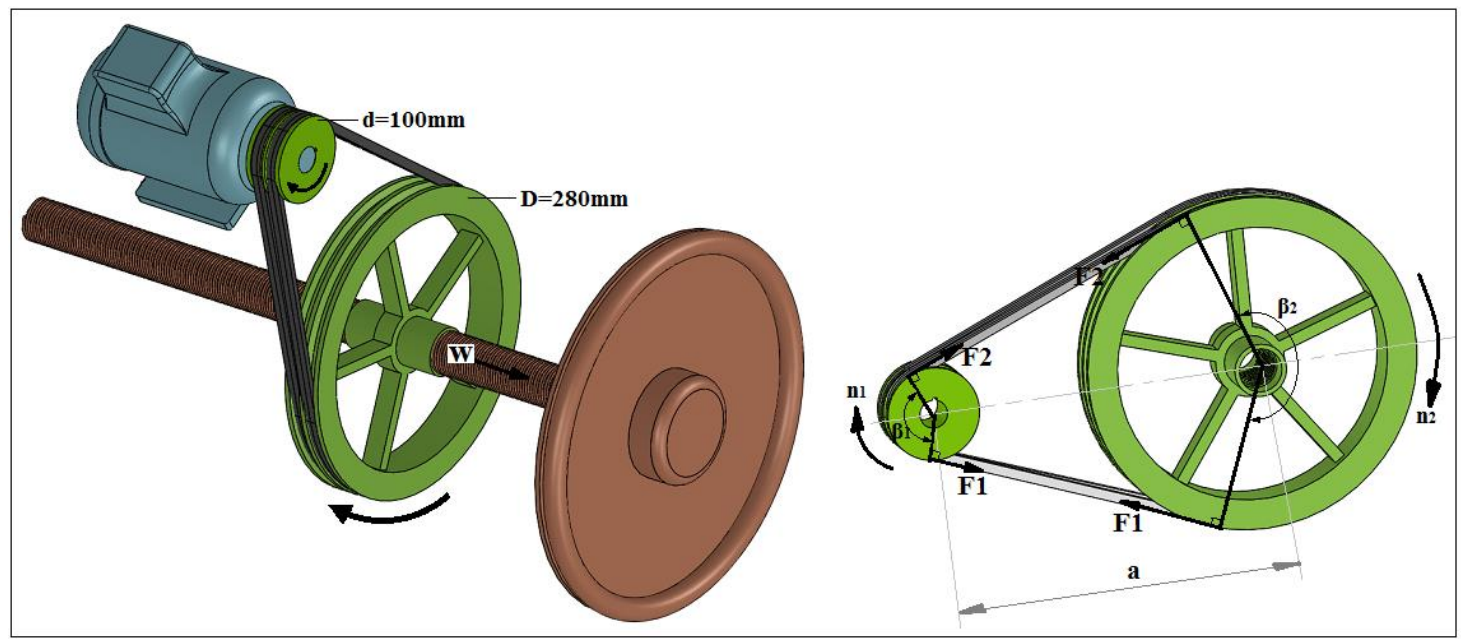

Şekil 1. Tahrik sistemi

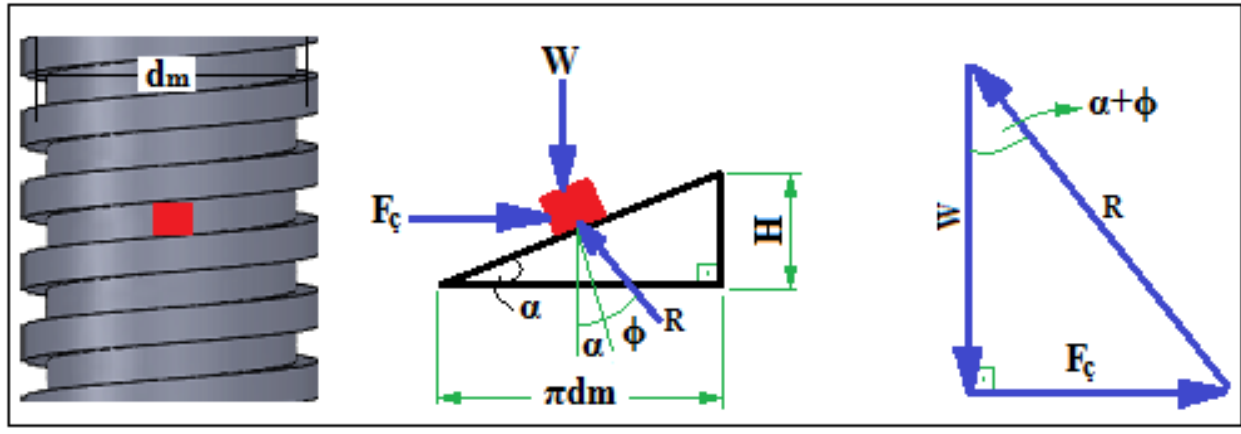

Şekil 2. Kare vida sistemi

$\underline{W=10000 N \text { için }}$

$\mathrm{d}_{\text {vida }}: 36 \mathrm{~mm}$, Vida adımı $(\mathrm{H}): 6 \mathrm{~mm}, \mathrm{dm}: 36-6 / 2=33 \mathrm{~mm}, \mu \mathrm{s}: 0,12$ ( çelik-çelik[7])

$\alpha=\tan ^{-1}\left(\mathrm{H} / \pi \mathrm{d}_{\mathrm{m}}\right)=\tan ^{-1}(6 / \pi 33) \quad \longrightarrow \alpha=3,3^{\circ}$ 


$$
\begin{aligned}
& \phi=\tan ^{-1}(\mu \mathrm{s})=\tan ^{-1}(0,12) \longrightarrow \phi=6,8^{\circ} \\
& \alpha+\phi=6,8+3,3=10,1^{\circ} \\
& \tan (\alpha+\phi)=\mathrm{F}_{\varsigma} / \mathrm{W} \quad \longrightarrow \quad \mathrm{F} c ̧=\mathrm{W} \times \tan (\alpha+\phi)=10000 \times \tan (10,1)=1781 \mathrm{~N} \\
& \mathrm{~F} 1=\mathrm{Fç} /\left(\mathrm{r}_{\text {kasnak }} / \mathrm{r}_{\text {vida }}\right)=1781 /(140 / 16,5) \longrightarrow \mathrm{F} 1=210 \mathrm{~N} \\
& \mathrm{~T}_{\mathrm{m}}=\mathrm{F} 1 \mathrm{x}(\mathrm{d} / 2)=210 \mathrm{x} 0,05=10,5 \mathrm{Nm} \longrightarrow \mathrm{W}=10000 \mathrm{~N} \text { için Motor torku }\left(\mathrm{T}_{\mathrm{m}}\right): 10,5 \mathrm{Nm} \\
& \mathrm{n}_{1}=\mathrm{n}_{2} \times(\mathrm{D} / \mathrm{d})=500 \times(280 / 100) \Longrightarrow \mathrm{n}_{1}=\mathrm{n}_{\mathrm{m}}=1400 \mathrm{dev} / \mathrm{dak} \\
& \mathrm{W}_{\mathrm{m}}=\left(\pi \mathrm{n}_{\mathrm{m}}\right) / 30=(\pi \times 1400) / 30 \longrightarrow \mathrm{w}_{\mathrm{m}}=146,5 \mathrm{rad} / \mathrm{s} \\
& \mathrm{P}_{\mathrm{m}}=\mathrm{T}_{\mathrm{m}} \times \mathrm{W}_{\mathrm{m}}=10,5 \times 146,5 \quad \mathrm{P}_{\mathrm{m}}=1538 \mathrm{~W}
\end{aligned}
$$

Motor katalogları incelenmiş ve hesaplanan değerlere en yakın olan $\mathrm{P}_{\mathrm{m}}=1,5 \mathrm{~kW}$ ve $\mathrm{n}_{\mathrm{m}}=1410$ dev/dak elektrik motoru seçilmiştir.

\section{$\underline{\text { Kaylș seçimi }}$}

$\mathrm{D}_{\text {kas }}: 280 \mathrm{~mm}, \mathrm{~d}_{\mathrm{kas}}=100 \mathrm{~mm}$, a: $300 \mathrm{~mm}$

$$
\begin{aligned}
& \beta_{1}=\pi-2 \sin ^{-1}((\mathrm{D}-\mathrm{d}) / 2 \mathrm{a})=\pi-2 \sin ^{-1}((280-100) / 2 \times 300) \quad \longrightarrow \quad \beta_{1}=145^{\circ}=2,53 \mathrm{rad} \\
& \beta_{2}=\pi+2 \sin ^{-1}((\mathrm{D}-\mathrm{d}) / 2 \mathrm{a})=\pi+2 \sin ^{-1}((280-100) / 2 \times 300) \longrightarrow \beta_{2}=215^{\circ}=3,75 \mathrm{rad} \\
& \mathrm{L}=\left[4 \mathrm{a}^{2}-(\mathrm{D}-\mathrm{d})^{2}\right]^{1 / 2}+\left(\mathrm{D} \times \beta_{2}+\mathrm{d} \times \beta_{1}\right) / 2 \\
& \mathrm{~L}=\left[4 \times 300^{2}-(280-100)^{2}\right]^{1 / 2}+(280 \times 3,75+100 \times 2,53) / 2 \longrightarrow \mathrm{L}=1223,5 \mathrm{~mm}
\end{aligned}
$$

Küçük kasnak çapı: $100 \mathrm{~mm}$ olduğu için A tipi kayış seçilmiştir. Kayış boyu $1223 \mathrm{~mm}$ hesaplanmıştır. Hesaplanan değere yakın olan boyu $1200 \mathrm{~mm}$ olan A tipi standart kayış seçilmiştir [8].

$$
\mathrm{V}_{\mathrm{kay} 1 \grave{s}}=\left(\pi \mathrm{dn}_{1}\right) / 60=(\pi \mathrm{x} 0,1 \times 1410) / 60 \quad \mathrm{~V}_{\mathrm{kay} 1 \grave{s}}=7,38 \mathrm{~m} / \mathrm{s}
$$

Literatürde $\mathrm{V}$ kayışların hızı $5-25 \mathrm{~m} / \mathrm{s}$ aralığında olması gerektiği ve bu değerlerin dışında olduğunda sorunlar ortaya çıktığı yer almaktadır [8]. Yapılan hesaplamada kayış hızı 7,38 m/s bulunmuştur. Kayış hızı istenilen değer aralığındadır. 


\section{$\underline{\text { Kaylș saylst }}$}

Kayış sayısı $\geq \mathrm{H}_{\mathrm{d}} / \mathrm{H}_{\mathrm{a}}$ olmalıdır.

$\mathrm{H}_{\mathrm{d}}=\mathrm{H}_{\mathrm{nom}} \mathrm{xK}_{\mathrm{s}} \mathrm{xn}_{\mathrm{d}}$

$\mathrm{H}_{\text {nom: }}: 1,5 \mathrm{~kW}, \mathrm{~K}_{\mathrm{s}}: 1$ (kısa süreli uniform çalışma), $\mathrm{n}_{\mathrm{d}}: 1$ (tasarım katsayısı)

$\mathrm{H}_{\mathrm{d}}=1,5 \times 1 \times 1=1,5$

$\mathrm{H}_{\mathrm{a}}=\mathrm{K}_{1} \times \mathrm{K}_{2} \mathrm{xH}_{\text {tablo }}$

$\mathrm{K}_{1}: 0,91\left(\beta_{1}=145^{\circ}\right.$ için), $\mathrm{K}_{2}: 0,95$ ( $\mathrm{L}=1,2 \mathrm{~m}$ için), $\mathrm{H}_{\text {tablo }}: 0,98\left(\mathrm{~V}_{\text {kayış }}=7,38\right.$ ve $\left.\mathrm{d}=100 \mathrm{~mm}\right)$

$\mathrm{H}_{\mathrm{a}}=0,91 \times 0,95 \times 0,98=0,85$

$\mathrm{H}_{\mathrm{d}} / \mathrm{H}_{\mathrm{a}}=1,5 / 0,85=1,76 \longrightarrow$ kayış sayıs $: 2$ adet

\section{2. İskelet Sisteminin Tasarımı ve yapısal analizi}

Şekil 3'de iskelet yapının CAD modeli görülmektedir. Presin iskelet yapısının tasarımı yapılırken sistemde etkili olan yük doğrultusu dikkate alınmıştır. Sistemde yük, eksenel doğrultuda etki etmektedir. Eksenel yükleri karşılamak için, bağlantı kolları iskelet yapıya açılı olarak konumlandırılmış ve kaynaklı olarak monte edilmiştir. Böylece yük doğrultusu radyal yöne değiştirilerek karşılanmıştır. Bu durumda bağlantı kollarında basma gerilmesi oluşacağ açıktır. Eğer düz olarak monte edilseydi bağlantı kollarında eğilme gerilmesi oluşacağı için dış çembere kaynaklanan kısmında kaynak bölgesinin dayanımı daha düşük olabilirdi.

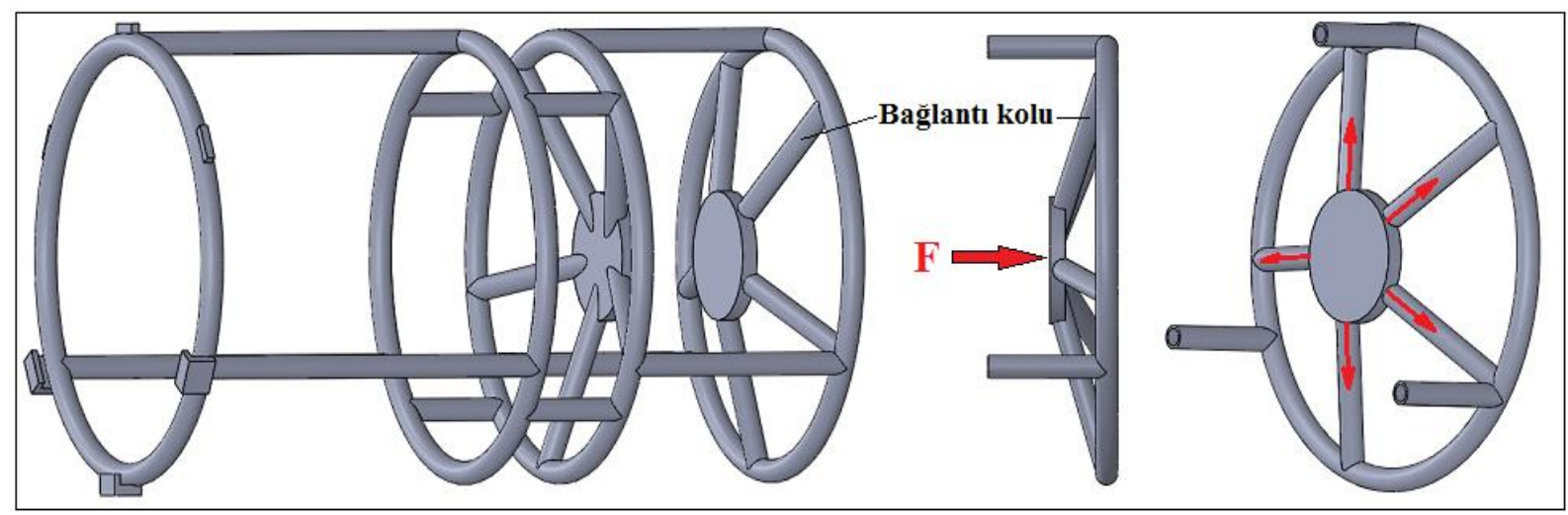

Şekil 3. İskelet yapı modeli 
İskelet yapı, ANSYS programının static stractural modülünde yapısal olarak analiz edilmiştir. Analiz sonuçları Şekil 4'de görülmektedir. Analiz sonuçları incelendiğinde maksimum deformasyonun en fazla 1,69 mm olarak meydana geldiği görülmüştür. Analizde von-Mises gerilmesinin en fazla 215,33 MPa olduğu tespit edilmiştir. İskelet yapı, düşük karbon çeliğinden oluşmaktadır. ANSYS malzeme kütüphanesinde ve kaynaklarda [9] bu malzemenin akma dayanımı 233-235 MPa ve çekme dayanımı 360-510 MPa olduğu yer almaktadır. Analizde ortaya çıkan maksimum gerilme (215,33 MPa) ve malzemenin akma dayanımı (235 MPa) karşılaştırıldığında iskelet yapıda kalıcı deformasyonların oluşmayacağı tespit edilmiştir. Analiz sonucunda presin çalışmasını olumsuz etkileyecek bir problem ortaya çıkmayacağı görülmüştür.
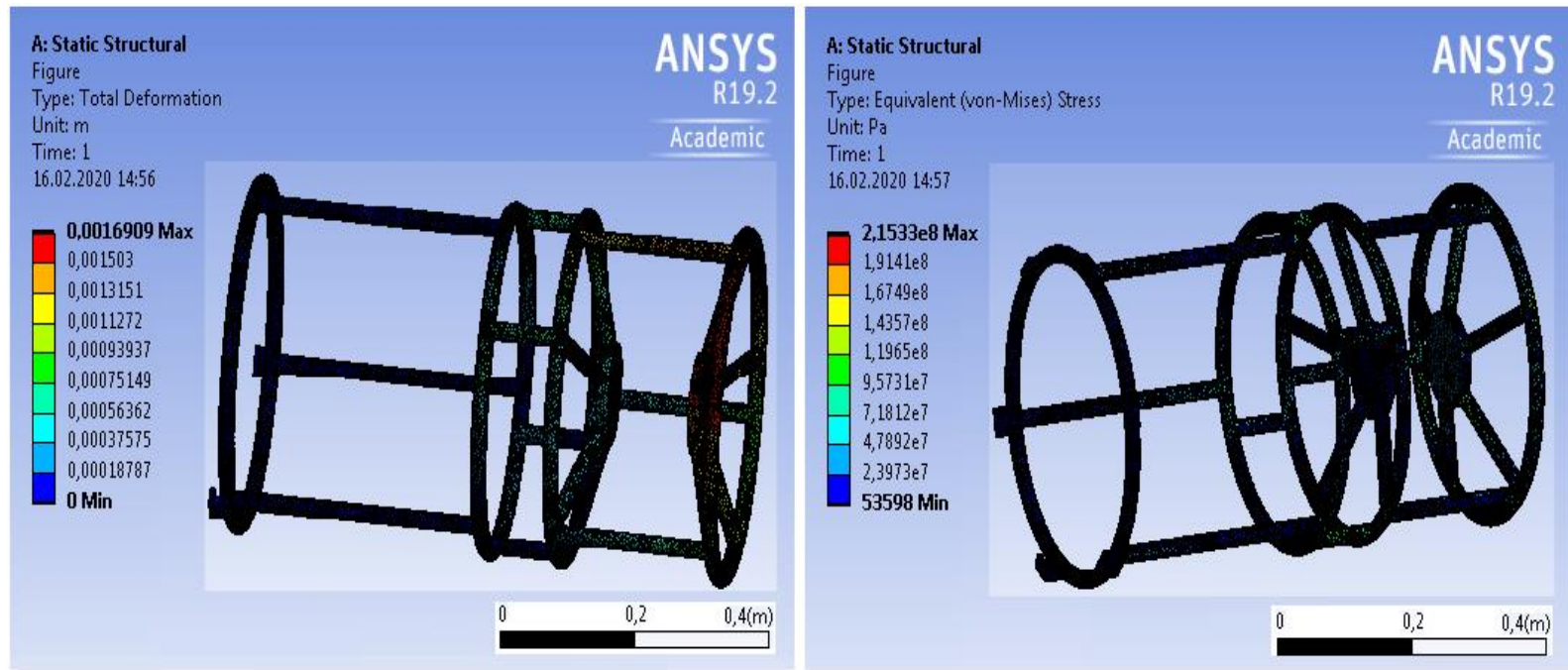

Şekil 4. Yapısal analiz sonucu

\subsection{Sıkıştırma Tablası ve Kapak Tasarımı}

Şekil 5'de presin sıkma tablası ve kapağı görülmektedir. Meyve püresinin etkin bir şekilde sıkılabilmesi için sıkma tablasının ortasına ve kapağın dış kısmına çıkıntılar (iç kısmı boş) oluşturulmuştur. Bu sayede püre çuvalı sıkılırken aynı zamanda büzülmeye zorlanmakta ve daha iyi sıkılmaktadır. 


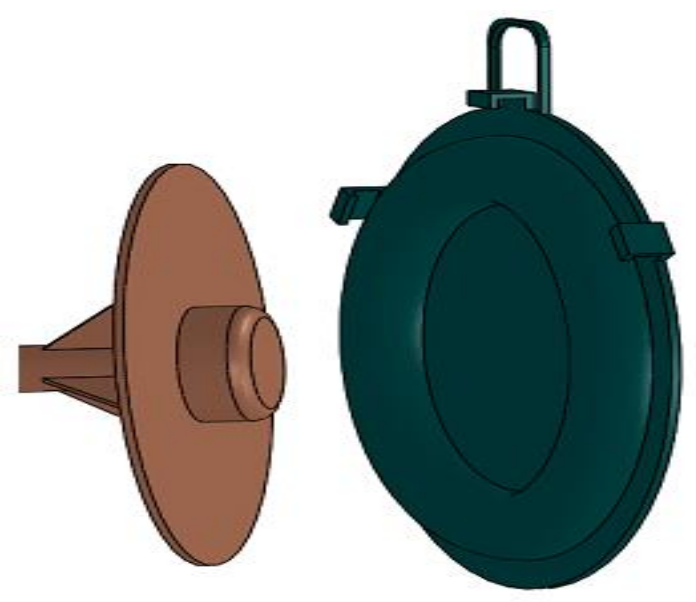

Şekil 5. S1kıştırma tablası ve kapak modeli

\section{Bulgular ve Tartışma}

Şekil 6 'da imal edeilen meyve sıkma presi görülmektedir. Meyve sıkma presi tasarlanan şekilde başarıyla üretilmiştir. Presin sıkma verimini bulmak için $24 \mathrm{~kg}$ elma püre haline getirilmiş ve ardından elde edilen püre sıkılarak suyu çıkartılmıştır. Sıłkma işleminden sonra püreden arta kalan küspe tartılmıştır. Hesaplandığında $17 \mathrm{~kg}$ su çıkartılmış ve \% 71 oranında sıkma verimi elde edilmiştir. Literatürde elma içerisindeki su oranının \% 84,5 olduğu belirtilmektedir [10]. Yapılan ölçümlerde, meyve sıkma presi sayesinde elma içerisindeki suyun büyük oranda çıkartıldığı tespit edilmiştir. Sıkma işlemi sonrası kalan küspe incelendiğinde pürenin iyi bir şekilde sıkılabildiği görülmüştür (Şekil 7b) .

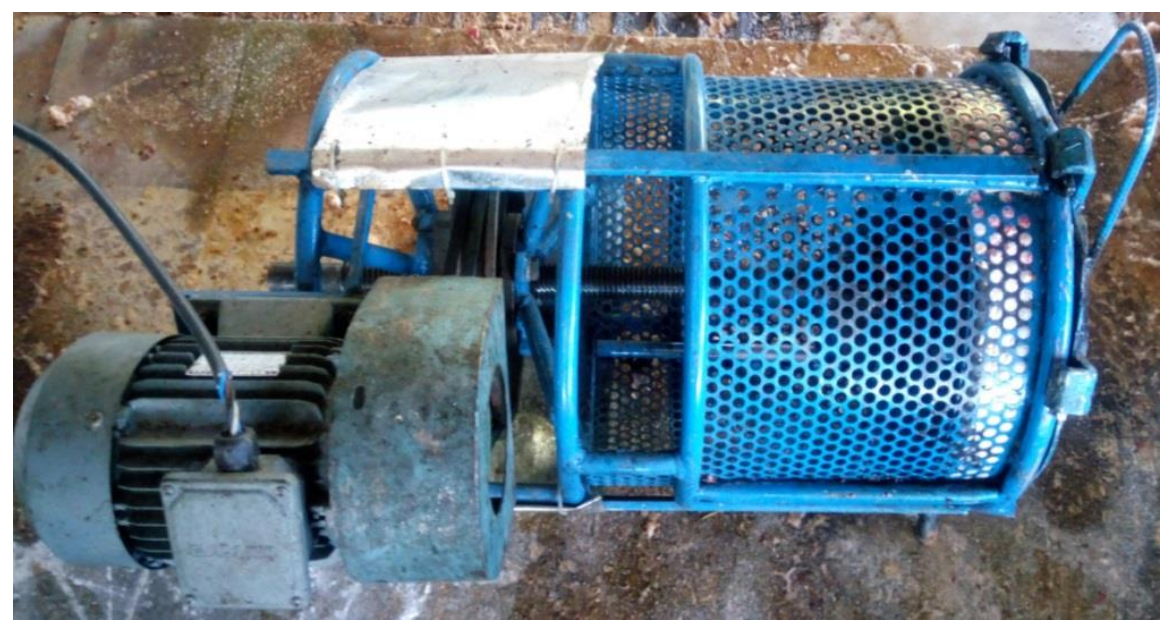

Şekil 6. Meyve sıkma presi 
Satılamayacak durumda olan ancak pekmez olarak değerlendirilebilecek elmalar meyve sıkma presi sayesinde suyu çıkartılmış ve pekmez olarak değerlendirilmiştir (Şekil 7a).
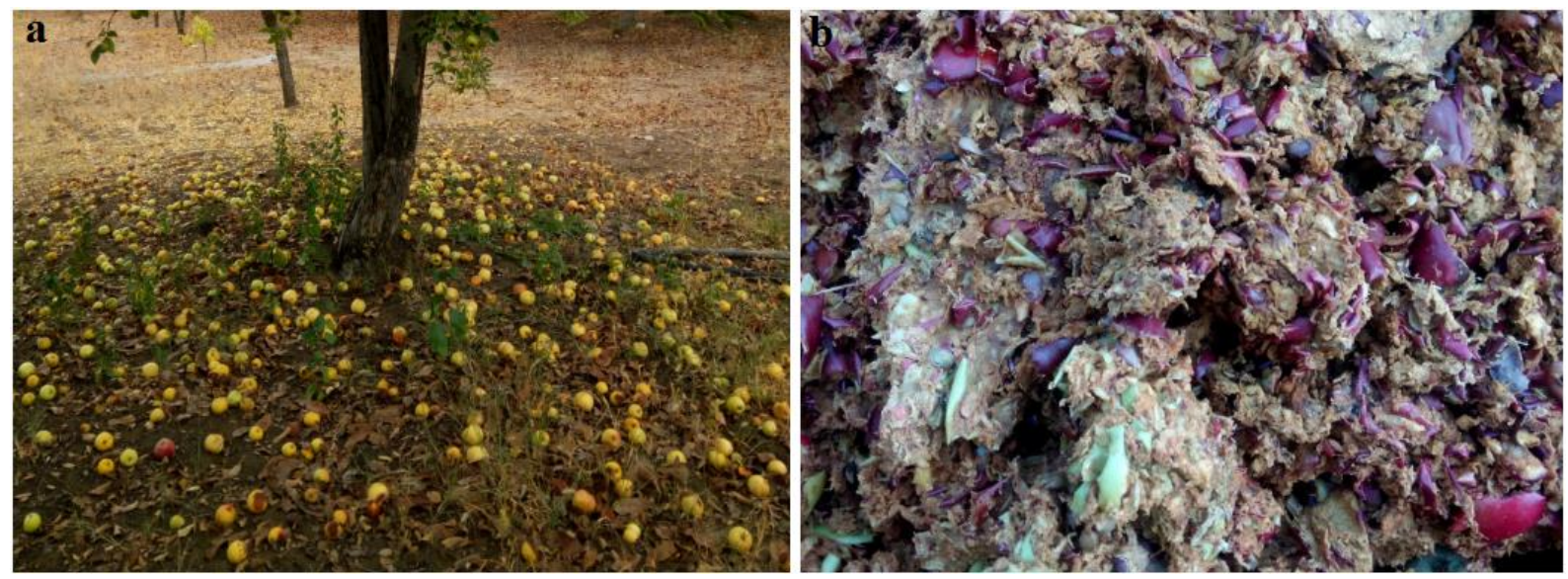

Şekil 7. Sıkılan elmalar ( a: sıkma öncesi, b: sıkma sonrası kalan küspe)

\section{Sonuçlar}

Meyve sıkma presi, 1 tonluk itme kuvveti sağlayacak şekilde tasarlandığı gibi başarıyla üretilmiştir. Hesaplamalar sonucu 1,5 kW gücünde 1410 devir elektrik motoru seçilmiş ve güç aktarımı için boyu $1200 \mathrm{~mm}$ olan 2 adet A tipi standart kayış kullanılması gerektiği belirlenmiştir. Yapısal analiz sonuçları incelendiğinde maksimum deformasyonun en fazla 1,69 $\mathrm{mm}$ ve von-Mises gerilmesinin en fazla 215,33 $\mathrm{MPa}$ olduğu tespit edilmiştir. Yapılan ölçümlerde, meyve sıkma presi sayesinde elma içerisindeki suyun \%71 oranında çıkartıldı̆̆ 1 bulunmuştur.

\section{Simgeler}

$\begin{array}{llll}\mathrm{H} & \text { : Vida adımı } & \mathrm{D} & \text { : Büyük kasnak çapı } \\ \mathrm{dm} & \text { : Ortalama vida çapı } & \mathrm{d} & : \text { Küçük kasnak çapı } \\ \mu \mathrm{s} & \text { : Statik sürtünme katsayısı } & \mathrm{a} & : \text { Kasnaklar arası mesafe } \\ \alpha & \text { : Vidanın helis açısı } & \beta_{1} & : \text { Küçük kasnak kavrama açısı } \\ \phi & \text { : Sürtünme katsayısının açı değeri } & \beta_{2} & : \text { Büyük kasnak kavrama açısı } \\ \mathrm{F}_{\mathrm{c}} & \text { : Vidaya gelen çevirme kuvveti } & \mathrm{L} & : \text { Kayış uzunluğu } \\ \mathrm{W} & \text { : Vidaya gelen eksenel kuvvet } & \mathrm{V} & : \text { Kayış hızı } \\ \mathrm{F} 1 & \text { : Kasnağı çeviren kuvvet } & \mathrm{H}_{\mathrm{d}} & : \text { Döndüren güç } \\ \mathrm{T}_{\mathrm{m}} & : \text { Motor torku } & \mathrm{H}_{\mathrm{a}} & : \text { Kayışı aktarabileceği güç }\end{array}$




$$
\begin{array}{ll}
\mathrm{n}_{1} & : \text { Küçük kasnak devri } \\
\mathrm{n}_{2} & \text { : Büyük kasnak devri } \\
\mathrm{n}_{\mathrm{m}} & : \text { Motor devri } \\
\mathrm{w}_{\mathrm{m}} & : \text { Motorun açısal hızı } \\
\mathrm{P}_{\mathrm{m}} & : \text { Motor gücü }
\end{array}
$$

$$
\begin{array}{ll}
\mathrm{H}_{\text {nom }} & \text { : Nominal güç } \\
\mathrm{K}_{\mathrm{s}} & \text { : İşletme katsayısı } \\
\mathrm{n}_{\mathrm{d}} & \text { : Tasarım katsayısı } \\
\mathrm{K}_{1} & \text { : Kavrama açısı düzeltme katsayısı } \\
\mathrm{K}_{2} & \text { : Kayış uzunluğu düzeltme katsayısı }
\end{array}
$$

\section{Kaynaklar}

[1] Yılmaz M., Pekmez ve Pekmeze Benzer Gıdalarda Taklit, Tağyiş ve Coğrafi Köken Tayini Araştırmas1, Basılı doktora tezi, İstanbul sanayi odası, 2019, ISBN: 978-605-137-137-5

[2] Karaca İ., Pekmez Orneklerinde Vitamin ve Mineral Tayini, Yuksek Lisans Tezi, İnonu Universitesi Sağlık Bilimleri Enstitusu, 2009, Malatya.

[3] Taşc1 F., Elma Ürün Raporu 2017, Tarımsal Ekonomi Ve Politika Geliştirme Enstitüsü, 2018, Yayın No: 296, Ankara

[4] Kaya, C., Yıldız, M., Hayoğlu, İ., \& Kola, O. Pekmez üretim teknikleri. GAP VI. Tarım Kongresi, 2005, 1482-1490.

[5] Şekercioğlu T., Kavramsal Tasarım Aşamalarında Bakımın Yeri ve Önemi, Mühendis ve Makine dergisi, 2019, 60 (694), 67-76.

[6] Mercin L., ve Diksoy İ.,Teknoloji ve tasarım, Millî Eğitim Bakanlığ1 Yayınları,2019, Ankara. (ISBN 978-975-11-4861-2)

[7] Rothbart H.A., Mechanical Design And Systems Handbook, 2. Ed. McGraw-Hill,1985, New York.

[8] Budynas, R. G., \& Nisbett, J. K. Shigley's mechanical engineering design. McGraw-Hill Education, 2020, 879.

[9] Hasçelik ürün kataloğu. URL: https://www.mib.org.tr/uploads/UserFile/Pdf/ bb2_j03TptWY9K0xvTmufHdojBnUCGQNHrAj.pdf, Son erişim tarihi: 19.02.2020

[10] Heybeli, N., \& Ertekin, C., Elma Dilimlerinin İnce Tabaka Halinde Kuruma Karakteristiği. Tarım Makinaları Bilimi Dergisi, 2007, 3, 179-187. 